\title{
PENGARUH SENAM KAKI PADA PENDERITA DIABETES MELLITUS TERHADAP SENSITIVITAS KAKI DI PUSKESMAS MULIOREJO KECAMATAN SUNGGAL KABUPATEN DELI SERDANG TAHUN 2019
}

\author{
Megawati \\ Jurusan Keperawatan Politeknik Kesehatan Kemenkes Medan
}

\begin{abstract}
Abstrak
Senam kaki diabetes adalah suatu kegiatan atau latihanyang dilakukan oleh pasien diabetes mellitus untuk mencegah terjadinya luka dan membatu melancarkan peredaran darah bagian kaki. Dengan tumit yang diletakkan di lantai, gerakan jari-jari kaki ke atas dan kebawah, ulangi sebanyak 2 - 10 kali (Suryadi, 2004). Adapun tujuan yang diperoleh setelah melakukan senam kaki adalah memperbaiki sirkulasi darah pada kaki pasien diabetes mellitus, sehingga nutrisi lancer ke jaringan tersebut (Tara, 2003). Sensitivitas kaki adalah kepekaan dari rangsangan pada ekstermitas bawah (ujung telapan kaki). Jenis penelitian ini menggunakan Prestest-Posttest Design, dimana penelitian ini dilakukan dengan cara melakukan pengamatan awal (pretest) terlebih dahulu dilakukan sebelum dilakukan intervensi. Setelah diberikan intervensi, kemudian dilakukan lagi pengamatan (posttest). Jumlah sampel dalam penelitian ini adalah 30 responden. Data diperoleh dari lembar observasi. Hasil penelitian didapat sebelum diberikan intervensi senam kaki sensitivitas kurang sebanyak 15 responden (50\%), sensitivitas sedang sebanyak 8 responden (26,7\%), sensitivitas baik sebanyak 7 responde $(23,3 \%)$ dan setelah dilakukan intervensi senam kaki meningkat menjadi sensitivitas sedang sebanyak 18 responden $(78,3 \%)$, sensitivitas baik sebanyak 5 responden $(21,7 \%)$. Hasil uji statistic didapat hasil yang signifikan terhadap peningkatan sesitivitas kaki dimana $p=0,00$ dengan nilai rata-rata peningkatan 0.67. Kesimpulan rata-rata senam kaki nilai sensitvitas sebelum dilakukan rendah. Setelah dilakukan senam kaki terhadap sensitivitas kaki terhadap sensitivitas kaki lebih tinggi. Disarankan agar keluarga ikut memberikan dukungan dan motivasi kepada pasien dalam melakukan senam kaki baik di rumah maupun saat pertemuan di Puskesmas.
\end{abstract}

Kata kunci : Senam Kaki, Sensitivitas Kaki

\section{PENDAHULUAN}

Diabetes mellitus tipe II adalah keadaan pankreas tetap menghasilkan insulin, kadang lebih tinggi dari normal tetapi tubuh membentuk kekebalan terhadap efeknya. Biasanya terjadi pada usia di atas 30 tahun karena kadar gula darah cenderung meningkat secara ringan tapi progresif setelah usia 50 tahun terutama pada orang yang tidak aktif dan mengalami obesitas (Smeltzer \& Bare, 2002).

Indonesia menempati urutan ke-4 terbesar dalam jumlah penderita diabetes mellitus di dunia. Pada tahun 2006 jumlah diabetes di Indonesia diperkirakan mencapai 14 juta orang, baru $50 \%$ yang sadar mengidapnyadan diantaranya baru sekitar 30\% yang datang berobat teratur (WHO, 2008).

Kebiasaan atau perilaku masyarakat seperti kurang menjaga kebersihan kaki dan tidak menggunakan alas kaki saat beraktifitas akan beresiko terjadi perlukaan pada daerah kaki. Keadaan kaki diabetic lanjut yang tidak ditangani secara tepat dapat berkembang menjadi suatu tindakan pemotongan amputasi kaki. Adanya luka dan masalah lain pada kaki merupakan penyebab utama kesakitan morbiditas, ketidakmampuan disadilitas,dan kematian mortalitas pada seseorang yang menderita diabetes mellitus (Soegondo, 2009).

Perawatan kaki merupakan upaya pencegahan primer terjadinya luka pada kaki diabetes maupun gejala awal adanya kesemutan atau baal yang akan menyebabkan penurunan sensitifitas kaki. Salah satu tindakan yang harus dilakukan dalam perawatan kaki untuk mengetahui adanya kelainan kaki secara dini adalah dengan melakukan senam kaki diabetes, selain memotong kuku yang benar, pemakaian alas kaki yang benar, dan menjaga kebersihan kaki (Soegondo, et al, 2004). Diabetes mellitus dapat diatasi dengan mengelola beberapa hal yang mempengaruhi penurunan glukosa, yaitu aktifitas, kadar insulin, diet, edukasi dan terpi (Perkeni, 2002: Smelzer \& Bare, 2002). Dilihat sudut ilmu kesehatan, tidak diragukan lagi bahwa olahraga atau latihan fisik apabila dilakukan sebagaimana mestinya menguntungkan bagi kesehatan dan kekuatan pada umumnya.

Intensitas yang dianjurkan sebesar $40-70 \%$. Aktifitas ringan sampai sedang (Ermita, 2009). Salah satu 
jenis olahraga yang dianjurkan pada penderita diabetes adalah senam kaki (Akhtyo, 2009).

Manfaat dari senam kaki diabet yang lain adalah dapat memperkuat otot-otot kecil, mencegah terjadinya kelainan bentuk kaki, meningkatkan kemampuan otot betis, dan paha, mengatasi keterbatasan gerak sendi, latihan seperti senam kaki diabet dapat membuat otot-otot dibagian yang bergerak berkontraksi (Soegondo, et all, 2008).

\section{METODE PENELITIAN}

Penelitian ini merupakan jenis penelitian kuantitatif dengan desain penelitian yaitu pra eksperimental one group. Kelompok subyek diobservasi sebelum dilakukan intervensi. Kemudian di observasi kembali setelah dilaksanakan intervensi (Sastroasmoro \& Ismael, 2010). Desain racangan yang dipergunakan yaitu pre and post test group design with control group.

Pengaruh senam kaki pada penderita diabetes mellitus terhadap sensitivitas kaki di Puskesmas Muliorejo Kecamatan Sunggal Kabupaten Deli Serdang Tahun 2019.

\section{LOKASI DAN WAKTU PENELITIAN}

Lokasi penelitian ini dilaksanakan di Puskesmas Muliorejo Kecamatan Sunggal Kabupaten Deli Serdang Medan, yang dilaksanakan mulai bulan Januari 2019 sampai bulan Juni 2019.

\section{POPULASI DAN SAMPEL}

\section{Populasi}

Populasi merupakan salah satu subjek atau objek dengan karakteristik tertentu yang akan diteliti. Bukan hanya objek atau subjek saja yang dipelajari tetapi seluruh karakteristik atau sifat yang dimiliki objek tersebut (Alimul, 2009). Populasi pada penelitian ini adalah seluruh pasien bulan Januari 2019 berjumlah 30 orang.

\section{Sampel}

Sampel adalah merupakan bagian dari populasi terjangkau yang dapat digunakan sebagai subyek penelitian melalui sampling (Nursalam, 2009). Menurut Sugiono (2006). Dalam penelitian ini tekhnik pengambilan sampel adalah Total sampling, yaitu mengambil kasus atau responden yang ada tersedia disuatu tepat sesuai dengan konteks penelitian (Notoadmodjo, 2010).

\section{HASIL DAN PEMBAHASAN}

\section{Hasil Penelitian}

\section{Analisa Univariat}

Analisa univariat dilakukan dengan menggunakan analisa distribusi, frekuensi, dan statistik deskriptif untuk melihat sensitivitas kaki sebelum dan sesudah dilakukan senam kaki.
Tabel 1. Distribusi Frekuensi karakteristik Responden di Puskesmas Muliorejo Kecamatan Sunggal Kabupaten Deli Serdang

No. Karakteristik Frekuensi Persen \%

\begin{tabular}{|l|l|c|c|}
\hline 1 & Usia & & \\
\hline & $26-45$ tahun & 7 & 23,3 \\
\hline & $46-55$ tahun & 18 & 60 \\
\hline & $56-65$ tahun & 5 & 16,7 \\
\hline & Total & 30 & 100 \\
\hline 2 & Jenis & & \\
\hline & Laki-laki & 21 & 70 \\
\hline & Perempuan & 9 & 30 \\
\hline & Total & 30 & 100 \\
\hline
\end{tabular}

Berdasarkan tabel 1 dapat dilihat bahwa mayoritas responden yang berusia 26-45 sebanyak 7 orang $(23,3 \%)$, yang berusia $46-55$ responden sebanyak 18 orang $(60,0 \%)$ dan yang berusia 56-65 sebanyak 5 orang $(16,7 \%)$. Sedangkan menurut jenis kelamin laki-laki sebanyak 21 orang $(70,0 \%)$ dan yang berjenis kelamin perempuan sebanyak 9 orang $(30,0 \%)$.

Tabel 2. Distribusi Frekuensi Sensitivitas Kaki Sebelum dilakukan Senam Kaki pada penderita diabetes Melitus di Puskesmas Muliorejo Kecamatan Sunggal Kabupaten Deli SerdangTahun 2019

\begin{tabular}{|c|c|c|}
\hline No. Sebelum Intervensi & Frekuensi & Persen \\
\hline 1 Sensitivitas Kurang & 15 & $50 \%$ \\
\hline 2 Sensitivitas Sedang & 8 & $26,7 \%$ \\
\hline 3 Sensitivitas Baik & 7 & $23,3 \%$ \\
\hline Total & 30 & $100 \%$ \\
\hline
\end{tabular}

Berdasarkan tabel 2 dapat dilihat bahwa mayoritas yang sensitivitas kaki yang kurang sebanyak 15 responden (50\%), yang sensitivitas kaki yang sedangsebanyak 8 responden $(26,7 \%)$ sedangkan yang sensitivitas kaki yang baik sebanyak 7 responden $(23,3 \%)$.

Tabel 3. Distribusi Frekuensi Sensitivitas Kaki Sesudah Dilakukan Senam Kaki Pada Penderita Diabetes Melitus di Puskesmas Muliorejo Kecamatan Sunggal Kabupaten Deli SerdangTahun 2019

\begin{tabular}{|c|c|c|}
\hline No. Sesudah Intervensi & Frekuensi & Persen \\
\hline 1 Sensitivitas Kurang & 15 & $0 \%$ \\
\hline 2 Sensitivitas Sedang & 8 & $78,3 \%$ \\
\hline 3 Sensitivitas Baik & 7 & $21,7 \%$ \\
\hline Total & 30 & $100 \%$ \\
\hline
\end{tabular}

Berdasarkan tabel 3 dapat dilihat bahwa mayoritas sensitivitas sedang sesudah diberikan senam kaki sebanyak 18 responden $(78,3 \%)$ sedangkan senstivitas baik sebanyak 5 responden $(21,7 \%)$.

\section{Analisa Bivariat}

Analisa Bivariat yaitu analisa yang dilakukan untuk mengetahui perbedaan sensitivitas kaki sebelum dan sesudah dilakukan senam kaki pada penderita diabetes. 
Analisa bivariat dilakukan dengan uji statistik Pair T test karena data berdistribusi normal.

Tabel 4. Distribusi Frekuensi Sensitivitas Kaki Sebelum dan Sesudah Dilakukan Senam Kaki Pada Penderita Diabetes Melitus di Puskesmas Muliorejo Kecamatan Sunggal Kabupaten Deli SerdangTahun 2019

\begin{tabular}{|c|c|c|c|c|}
\hline No. & Sensitivitas Kaki & Mean & SD & PValue \\
\hline 1 & Sensitivitas Kaki sebelum & & & \\
\hline & dilakukan intervensi & 1,76 & 0,81 & 0,00 \\
\hline 2 & Sensitivitas kaki setelah & & & \\
\hline & dilakukan intervensi & 2,43 & 0,5 & 0,00 \\
\hline
\end{tabular}

Dari tabel 4 dapat dilihat bahwa terdapat perbedaan rata-rata sensitivitas kaki yang bermakna antara sebelum dan sesudah dberikan intervensi (P Value $<0,05$ ). Sesudah dilakukan intervensi terjadi perubahan rata-rata sensitivitas kaki sebanyak 0,67.

\section{Pembahasan}

Hasil penelitian ini sesudai dengan penelitian sebelumnya yaitu Calle, Pascual, Duran, (2001) menyatakan bahwa diabetisi dengan neuropati dilakukan perawatan kaki diabet yang dilakukan dengan menjaga sirkulasi darah atau kaki dihasilkan kelompok yang tidak melakukan perawatan kaki 13 kali beresiko terjadinya ulkus diabetika dibandingkan kelompok yang melakukan perawatan kaki secara teratur.

Hal ini sesudai dengan penelitian sahar (2002) yang menyebutkan bahwa ada peningkatan keterampilan secara signifikan setelah 6 bulan penelitian tersebut menunjukkan terjadinya peningkatan keterampilan atau latihan sedangkan esensi perbedaan penelitian tersebut selama 6 bulan, sedangkan penelitian ini dilakukan selama 2 minggu.

Begitu pula penelitian Barnett, et, al (2003) mengemukakan bahwa latihan fisik yang dilakukan 1 jam per minggu selama satu tahun dapat menurunkan angka kerusakan sebesar $40 \%$. Intensitas dan kontinuitas dalam melakukan aktivitas atau latihan akan mempengaruhi efek yang ditimbulkan. Oleh karena itu senam kaki yang dilakukan secara teratur dan seimbang dapat berdampak positif bagi penderita Diabetes Melitus.

Perkini (2006) menyatakan perawatan kaki diabetesi yang teratur akan mencegah atau mengurangi terjadinya komplikasi kronik pada kaki.

Menurut Waspadji (2014), senam kaki merupakan salah satu terapi yang diberikan seorang perawat, yang bertujuan untuk memperlancar peredaran darah yang terganggu karena senam kaki diabetes dapat membantu memperkuat otot-otot kaki.

\section{KESIMPULAN DAN SARAN}

\section{Kesimpulan}

1. Rata-rata sensitivitas kaki sebelum dilakukan senam kaki nilai sensitivitas kaki lebih rendah.

2. Rata-rata sensitivitas kaki setelah dilakukan senam kaki nilai sensitivitas kaki lebih tinggi.

3. Ada pengaruh sebelum dan sesudah dilakukan senam kaki terhadap sensitivitas kaki pada penderita diabetes mellitus di Puskesmas Muliorejo Kecamatan Sunggal Kabupaten Deli Serdang Tahun 2019.

\section{Saran}

1. Keluarga Bersama dengan Pasien

Agar keluarga ikut memberikan dukungan dan motivasi kepada pasien dalam melakukan senam kaki baik di rumah maupun saat pertemuan di Puskesmas.

\section{Penelitian Lanjutan}

Perlu diteliti lebih lanjut dengan menggunakan variabel lain yang dapat mempengaruhi sensitivitas kaki seperti faktor obat-obatan, penyakit yang diderita, makanan dan minuman serta kekuatan otot. Perlu dikembangkan untuk penelitian yang akan datang mengenai lamanya intervensi, waktu latihan senam kaki, pagi atau sore.

\section{DAFTAR PUSTAKA}

Akhtyo, (2009). Gambaran Klinis Hipoglikemia Pada Pasien Diabetes Melitus.

Alimul Aziz, H. (2009). Populasi dan Sampel. Edisi 2. Jakarta: Salemba Medika.

Sigit Priyanto, (2012), Pengaruh Senam Kaki Terhadap Sensitivitas Kaki pada Penderita Diabetes Melitus di Magelang. Jakarta : FIK UI. Hal.3

Notoatmodjo, S. (2010). Teknik Pengambilan Sampel. Jakarta: Rineka Cipta.

Nursalam (2009). Konsep \& Penerapan Metodologi Penelitian Ilmu Kesehatan Pedoman Skripsi, Tesis dan Instrumen Penelitian Keperawatan, Jakarta : Salemba Medika.

Perkini, (2006). Consensus Pengelolaan Diabetes Melitus Di Indonesia. Jakarta : PB Perkini.

Smeltzer \& Bare. (2002). Keperawatan Medikal Bedah Volume 2. Alih Bahasa Andry Hartono. EGC : Jakarta.

Soegondo. (2009). Melawan Diabetes dengan Banyak Beraktivitas, diakses dari http://www.indodiabetes.com.

Waspadji, (2014). Senam kaki Jakarta: Badan Penerbit Fakultas Kedokteran Universitas Indonesia 